\title{
Article \\ Automotive Body Shop Design Problems Using Meta-Models Considering Product-Mix Change and Reconfiguration Strategy
}

\author{
Dug Hee Moon ${ }^{1, * \mathbb{D}}$, Dong Ok Kim ${ }^{2}$ and Yang Woo Shin ${ }^{3}$ \\ 1 Department of Industrial and Systems Engineering, Changwon National University, Changwon 51140, Korea \\ 2 Department of Eco-Friendly Marine Plant FEED Engineering, Changwon National University, \\ Changwon 51140, Korea; positive_ok@naver.com \\ 3 Department of Statistics, Changwon National University, Changwon 51140, Korea; ywshin@changwon.ac.kr \\ * Correspondence: dhmoon@changwon.ac.kr; Tel.: +82-10-2586-7543
}

check for updates

Citation: Moon, D.H.; Kim, D.O.; Shin, Y.W. Automotive Body Shop Design Problems Using Meta-Models Considering Product-Mix Change and Reconfiguration Strategy. Appl. Sci. 2021, 11, 2748. https:// doi.org/10.3390/app11062748

Academic Editor: Maurizio Faccio

Received: 7 February 2021

Accepted: 15 March 2021

Published: 18 March 2021

Publisher's Note: MDPI stays neutral with regard to jurisdictional claims in published maps and institutional affiliations.

Copyright: (c) 2021 by the authors. Licensee MDPI, Basel, Switzerland. This article is an open access article distributed under the terms and conditions of the Creative Commons Attribution (CC BY) license (https:// creativecommons.org/licenses/by/ $4.0 /)$.

\begin{abstract}
The estimation of production rate (or throughput) is important in manufacturing system design. Herein, we consider the manufacturing system of an automotive body shop in which two types of car are produced, and one car (engine car) is substituted by the other car (electric car) gradually. In this body shop, two different underbody lines are installed because the underbody structures of the two types of cars differ completely; however, the side body line and main body line are shared by the two cars. Furthermore, we assume that the underbody lines are reconfigurable based on an increase in the product mix of the electric car. A simulation-based meta-model, which is in the form of a quadratic polynomial function, is developed to estimate the production rate. In the meta-modelling process, we group some buffer locations and represent them as one variable to reduce the number of variables included in the meta-model. Subsequently, the meta-models have been used to optimize two types of buffer allocation problems, and optimal solutions are obtained easily.
\end{abstract}

Keywords: manufacturing system design; automotive body shop; product-mix; reconfiguration; meta-model; simulation

\section{Introduction}

The role of an automotive body shop is to assemble sheet metal panels together by various welding technologies [1]. A typical car undergoes 3500 to 4000 spot welds [2]. Large cars, such as the Rover 75, undergo 5400 spot welds, of which 3000 spots are re-spot welds [3]. In the case of compact cars produced by a Korean automotive manufacturer, the total number of welding points is $4500-5400$ and $50-55 \%$ of them are operated in house.

The body shop of an automotive factory is highly automated and comprises complex manufacturing systems involving 15-20 sublines and many assembly operations [4]. In general, the sublines of a body shop can be categorized into a few groups, such as underbody lines, side body lines, main body lines, opening parts (attachments) lines, and body in white lines. In the design phase of automotive body shops, many factors must be considered, such as the line concept, number of sublines, length of each subline, locations and capacities of buffers, line balancing, robot type, material handling equipment, and tooling. Moon et al. [4] has described the processes in automotive body shop design.

The mixed-models production, which means two or more types of cars are produced in the same line (or shop), is popular in automotive industries, even in a body shop. Hansen et al. [5] has introduced that an average of five car variants are produced in a single body shop, and this will increase to eight variants. In general, different cars with similar body framing and similar operations enable a mixed-model production by changing jigs, fixtures, and welding robot programs automatically [5]. As the demand for eco-friendly (low carbon) cars such as hybrid cars or electric cars is increasing, most automotive companies are obliged to change the layout concept of their body shops [6-8]. In general, they produce 
both hybrid cars and internal combustion engine cars (we refer to it as an engine car) in the same body shop because both cars can share the same body platform. For a hybrid car with front-wheel drive, engine, motor, and transmission are installed in the front area of the car body (engine room), whereas the battery pack and fuel tank are typically installed in the rear area of the car body. However, in an electric car, a flat battery pack is installed on the entire underbody to account for weight balance $[7,8]$. Hence, the underbody structure of an electric car differs from that of an engine car by its fully enclosed, smooth underbody (known as the "skateboard platform"). Furthermore, the material of the underbody of an electric car may be different from that of an engine car, thereby resulting in different adhesive operations. Therefore, underbody lines tend to be separated to two in automotive manufacturing, i.e., one for the engine car (or hybrid car) and the other for the electric car. This is investigated in our study.

Another situation considered in this study is reconfiguration. Koren $[9,10]$ defined the reconfigurable manufacturing system (RMS) as 'RMS is a production system designed to match the dynamic market asking for high-quantity products in variable quantities and at a reasonable cost. RMS has a changeable hardware and software structure allowing adjusting production capacity and functionality to combine high throughput rate, flexibility and cellular organization pattern.' In the survey paper written by Bortolini et al. [11], the research areas related to RMS have been grouped as five: reconfigurability level assessment; analysis of RMS features such as modularity, integrability, diagnosibility, convertibility, customization and scalability; analysis of RMS performances; applied research and field applications; and reconfigurability toward Industry 4.0 goals.

Initially, the production quantity of electric cars is small; however, the demand for electric cars increases gradually and electric cars will substitute engine cars. Hence, the capacity of the underbody line of an electric car should be expanded, and that of an engine car should be downsized. This means that the layouts of the two types of cars should be changed, and this necessitates reconfiguration of underbody lines. Hence, although the configurations of manufacturing system are not changed dynamically, the situation can be defined as the simple case of reconfiguration. Moon et al. [12] presented a brief simulation study regarding reconfiguration strategies in a body shop which is shown in Figure 1, and an extension of that study is presented herein.

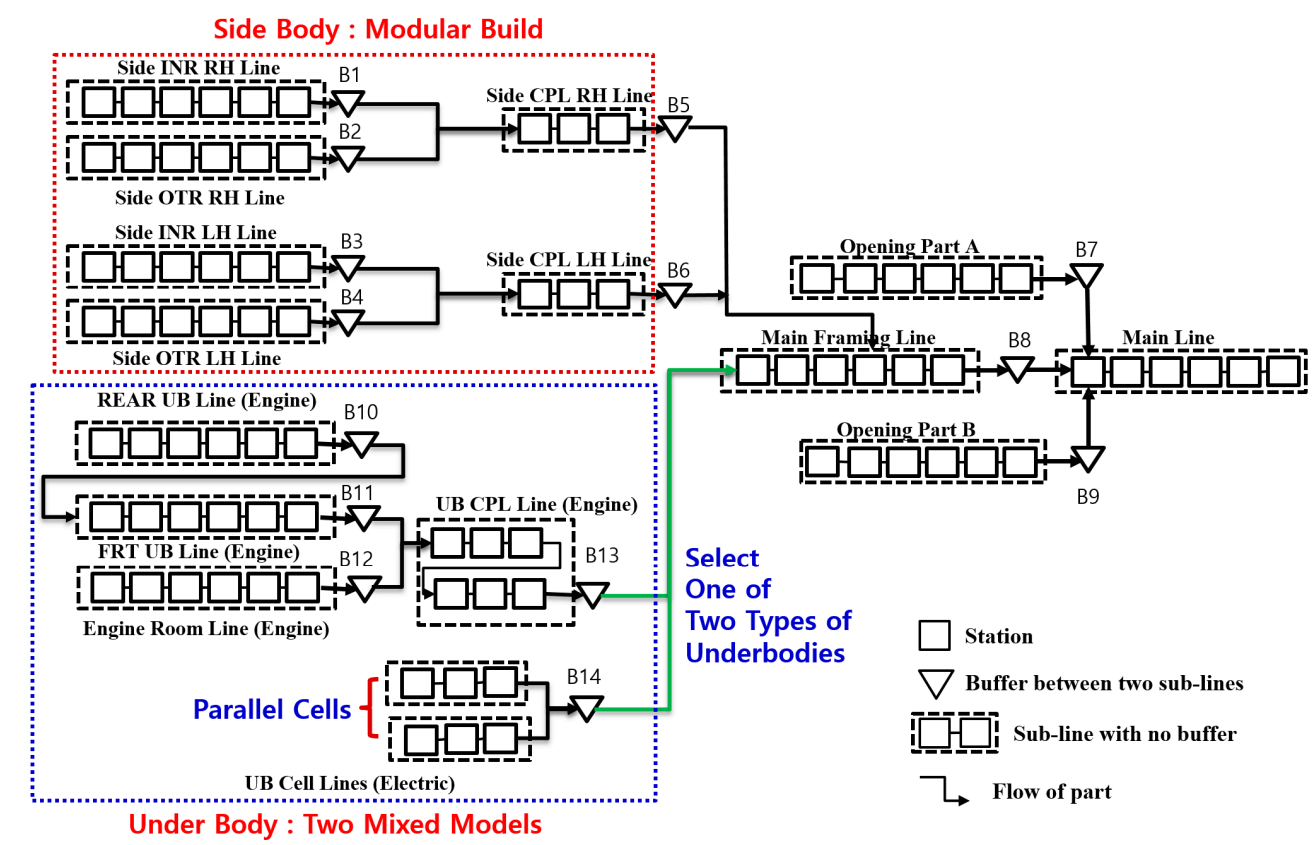

Figure 1. Abstract model of an automotive body shop [12]. 
In this study, we develop meta-models that can estimate the production rate when the product mix is changed in an automotive body shop; additionally, we investigate the effects of reconfiguration strategies. The developed meta-models are applied to two optimal buffer allocation problems (BAP); the first is the maximization problem of production rate and the other is the maximization problem of profit. This paper is organized as follows. In Section 2, the related topics and articles are introduced, and the system configuration is described in Section 3. In Section 4, meta-modelling processes using simulations are explained, and the validity of the meta-models are addressed. In Section 5, the developed meta-models are applied to solve two optimization problems, and conclusions are presented in Section 6.

\section{Related Topics and Literatures}

This study combines three subjects; a special automotive manufacturing system as the application area, simulation-based meta-modeling for evaluating performance measures, and optimization problems such as BAP (buffer allocation problems). Hence, related literatures are reviewed separately according to the three subjects. Table 1 compares some important articles (excluding survey papers and books) introduced in this section with respect to the type of manufacturing system, the number of products, performance evaluation method, and the type of objective functions.

\subsection{Automotive Body Shop Design}

To determine the final design of an automotive body shop, many iterative steps are required, and the performance of the system should be evaluated at each step. Hence, the evaluation of the performance measures is crucial. Only a few studies have considered the manufacturing systems of automotive body shops. Muhl, Charpentier, and Chaxel [13] and Tahar and Adham [14] explained the overall processes of an automotive factory and introduced some issues.

Spieckermann et al. [15] presented a simulation-based optimization approach for the body shop design problem, and they used meta-heuristics for solving the problem. However, their simulation model was simpler than our model because they assumed the sublines as a station; therefore, the time required for optimization was not a serious problem. Moon et al. [4] published a case study regarding the design procedure and design analysis of an automotive body shop using three-dimensional simulations. Feno, Cauvin, and Ferrarini [16] proposed a design process for the early phase of automotive body shop design and explained the integration of digital manufacturing technologies and simulations. Recently, Giampieri et al. [6] published a review paper regarding automotive manufacturing systems in the context of energy.

Kim et al. [17] compared two different layouts in automotive body shops, the layered build method and the modular build method, with respect to welding methods in side body sublines. In this study, they conclude that modular build method is more efficient. Moon et al. [18] compared two types of part transfer policies that are applicable to sublines without any buffer: the synchronous and asynchronous transfer. Generally, asynchronous transfer is better than synchronous transfer with respect to production rate, but more investment cost is required. Moon, Nam, and Shin [19] suggested that the throughput gap between two layout structures can be reduced by decoupling the main body subline and optimizing buffer allocations. However, these studies assumed only one type of car and did not include underbody sublines. Moon, Lee, and Shin [20] investigated the effect of mixed-model production in a body shop through simulations, but they did not consider underbody lines.

There have been some articles dealing with the element technologies applicable to the design of an automotive body shop. Kahan et al. [21] presented a backup strategy in which working robots perform tasks of failed robots. They proposed that a mixed-integer linear-programming-based approach minimizes the throughput loss by utilizing the robots redundancy in the system. Azzi et al. [22,23] introduced a mixed model assembly line balancing problem (MALBP) and mixed model sequencing problem (MMS) in unpaced 
assembly lines which consisted of a main line and multiple feeder lines using simulation and optimization models. Although their systems were not specified as an automotive body shop, they were worthwhile to analyze the subsystems of a body shop. Collaborative assembly systems in which human and robots are working together (see [24]) could be applicable to the design of opening parts sublines.

\subsection{Performance Evaluating Methods for Manufacturing System Design}

In manufacturing system design, the processes, process time, and process equipment required for manufacturing products must be identified. Furthermore, the method to construct the most efficient layout, and the prediction of various performance measures, such as throughput (or production rate), work-in-process (WIP), and manufacturing lead time, as well as the utilization of each resource must be considered. Additionally, both investment and operating costs should be considered in the design phase of a manufacturing system.

To solve manufacturing system design problems, one must firstly estimate the performance measures. Two approaches are typically used to evaluate the performance measures of manufacturing systems: simulations and stochastic models, such as the queuing network theory or Markovian processes [25,26].

\subsubsection{Stochastic Modeling}

Stochastic modelling has been widely used in the past decades, and the analysis of manufacturing systems such as flow lines, parallel lines, and assembly lines considering finite (or infinite) buffers and reliable (or unreliable) servers are abundant in the literature [25-30]. Recently, Papadopoulos, Li, and O'Kelly [31] published a survey paper that classified prior studies using the Markov model in manufacturing system design into system types, objectives, and approaches. In their paper, system types were classified into flow lines, job shops, flexible manufacturing cells, and assembly systems. Among them, the most popular system considered was flow lines (serial lines), and the objective was to estimate the throughput of the system.

Systems comprising only two or three machines can be analyzed through stochastic modelling, from which exact solutions can be obtained. However, it is typical to analyze a complex manufacturing system using the approximation approach because of limitations due to difficulties in modelling and solving. The assembly line is more complex than the flow line; hence, its mathematical analysis is more difficult [31]. For assembly lines, most studies that obtained an exact solution for the prediction of throughput are for systems comprising only one assembly process. Recently, Tancrez [32] presented an approximation method using decomposition for assembly/disassembly systems with general processing time distributions and a finite buffer, but the system considered was relatively simpler than our systems.

\subsubsection{Simulation}

Simulation is widely used because of its relatively easy application in designing and analyzing complex systems. Cohen et al. [33] predicted that the advances in Industry 4.0 would provide both challenges and opportunities for digital manufacturing and assembly systems, and one of the key technologies must be a simulation. All articles addressed in Section $2.1[4,13-21]$ used simulation for evaluating the performances of the systems. However, many replicative tasks are required to solve optimization problems using simulation, such as modifying simulation models, changing parameters, and performing additional experiments. These limitations further complicate the simulations when the number of factors to be optimized increases. Another problem in simulations is that the results may fluctuate in the vicinity of the optimal solution owing to randomness. For example, the production rate should increase when the buffer capacity increases additionally from the current capacity; however, the production rate may decrease slightly owing to randomness in the simulation, thereby affecting the convergence of the objective. This problem is inevitable when using an approximate method or simulations. 


\subsubsection{Meta-Modeling}

Meta-modelling methods based on simulation have been used to overcome limitations such as convergence due to randomness as well as significant amounts of experimental costs and time. Meta-models are also known as response surface, surrogates, or auxiliary models; they are defined as functions that describe the relationship between the input and output of the target system [34]. According to Can and Heavy [35], meta-models using discrete event simulation may be a good alternative for satisfying the accuracy and cost required for optimization problems. The meta-model is classified into a method using an analytic model such as the linear regression model, and a black-box model such as artificial intelligence. Kleijnen and Standridge [36] proposed a meta-modelling method that uses two types of regression models in simple flexible manufacturing system lines to predict throughput. Durieux and Pierreval [37] introduced a meta-model using regression for a system involving logistics equipment in an automated line composed of parallel machines, and they analyzed the effects of design factors on system efficiency using the meta-model. Recently, Motlagh et al. [38] developed a meta-model for evaluating throughput in unreliable, unbalanced serial lines, and applied the meta-model to optimization problems. In addition, Dengiz and Akbay [39], Um, Cheon and Lee [40], Dengiz, Tansel İç, and Belgin [41], and others investigated meta-modelling methods using regression methods in various manufacturing system design problems. However, the system considered in this paper is more complex than the systems in the papers introduced above.

Table 1. Comparison of references.

\begin{tabular}{|c|c|c|c|c|c|c|}
\hline \multirow{2}{*}{ References } & \multirow{2}{*}{ Manufac. Sys. Types } & \multirow{2}{*}{ Products } & \multirow{2}{*}{ Performances } & \multicolumn{2}{|c|}{ Performance Analysis Methods } & \multirow{2}{*}{ Objectives } \\
\hline & & & & Sim. & Meta & \\
\hline Spieckermann [15] & AL(FABS) & Single & $\mathrm{PR}, \mathrm{CT}$ & $\bullet$ & & Min. Cost \\
\hline Kahan [21] & AL(PABS) & Single & $\mathrm{CT}$ & $\bullet$ & & Comp. \\
\hline Feno [16] & AL(PABS) & Multiple & $\mathrm{CT}, \mathrm{TP}$ & $\bullet$ & & Comp. \\
\hline Kim [17] & AL(PABS) & Single & PR & $\bullet$ & & Comp. \\
\hline Moon [4] & AL(FABS) & Single & $\mathrm{TP}$ & $\bullet$ & & Max. TP \\
\hline Moon [18] & AL(PABS) & Single & PR, LT & $\bullet$ & & Comp. \\
\hline Moon [19] & AL(PABS) & Single & PR, LT & $\bullet$ & & Max. PR \\
\hline Moon [20] & AL(PABS) & Multiple & PR, LT & $\bullet$ & & Comp. \\
\hline Can [35] & FL & Single & TR & & $\bullet$ & Max TP \\
\hline Dengiz [39] & FL & Single & $\mathrm{PR}, \mathrm{CT}$ & & $\bullet$ & Comp. \\
\hline Motlagh [38] & FLP & Multiple & TP, WIP, & & $\bullet$ & Multi. \\
\hline Dengiz [41] & FLR & Multiple & $\mathrm{TP}$ & & $\bullet$ & Max. TP \\
\hline Kleijnen [36] & FMS & Single & $\mathrm{TP}$ & & & Max TP \\
\hline Durieux [37] & FMS & Multiple & Util. & & $\bullet$ & - \\
\hline Um [40] & FMS & Multiple & TP, AGV Util. etc. & & $\bullet$ & Multi. \\
\hline This paper & AL(FABS) & Multiple & PR & & $\bullet$ & $\begin{array}{c}\text { Max. PR, } \\
\text { Max. Profit }\end{array}$ \\
\hline
\end{tabular}

FL: Flow lines; FLP: Flow line with parallel machine; FLR: Flow line with re-entrance; FMS: Flexible manufacturing system (or cell); AL: Assembly lines; FABS: Full automotive body shop (relatively); PABS: Part of automotive body shop; PR: Production rate; TP: Throughput; CT: Cycle time; LT: Lead time; Util.: Utilization of resource; WIP: Work-in-process; Comp.: Comparison strategies; Multi: Multiple objectives.

\subsection{Buffer Allocation Problem (BAP)}

The most representative optimization problem studied in the design of manufacturing systems is the buffer allocation problem (BAP), which is to determine the optimal buffer size for each buffer location when the total number of buffers is determined [42]. BAP is classified according to four criteria as follows. The first is about the system types such as flow lines, flexible flow lines, assembly lines and so on, and the most widely studied area is flow lines. The mathematical formulation of optimal buffer allocation in assembly lines is basically similar to that of the flow lines, but there is a difference in that the method of evaluating the value of the objective function, such as production volume and system residence time, is relatively complicate.

The second is the classification according to the type of objective function. The most representative objective function is to maximize the production rate (or throughput), 
and there are various objective functions such as minimizing investment and operating costs, maximizing profits, and multi objectives. The third criterion is according to the optimization methodologies such as genetic algorithm and various meta-heuristics. Finally, as mentioned in Section 2.2, the fourth classification is the approaches used for performance evaluation such as stochastic models, simulations, and meta-models. Since there have been many survey papers related to BAP [42-47], we will not discuss BAP anymore.

\section{System Configurations}

\subsection{Basic Configuration}

For our system, we assume that the welding method of the side body is the modular build method [17] and the transfer policies in all sublines are asynchronous transfer [18]. To evaluate the reconfiguration strategies for underbody lines in an automotive body shop, we defined the abstract model of the automotive body shop as shown in Figure 1, and the following assumptions were applied to the system:

1. Both the engine and electric cars are produced for the same car model. The total target production volume is fixed, but the individual production volume can be changed according to the product mix.

2. All sublines except for the underbody lines are typically shared. However, two types of underbody lines exist: one for the engine car and the other for the electric car. The layout of the underbody lines for the engine car is similar to the traditional layout. However, the structure of underbody lines for the electric car is designed based on the concept of a cell system owing to the low production volume. When the production volume of the electric car increases, we can install additional cell lines in parallel.

3. Buffers exist between two sublines (total number of buffer locations is 14); however, no buffer exists between two successive stations in a subline.

4. The process times (PT) of all stations in sublines for the upper body (side body and main body) and the opening parts are constant and known as one time unit (minute) because a body shop is a highly automated manufacturing system.

5. The PTs of the underbody lines (cells) can be changed according to the change in the product mix of two types of cars. The total workload is fixed; hence, the process time of a workstation is determined by the number of work stations. We assume that a perfect line balancing is possible.

6. Only one mode of time-dependent failure exists for all workstations, and the distributions of time-to-failure (uptime) and time-to-repair (downtime) are exponentially distributed.

7. No starvation occurs in the first stations, and no blocking occurs in the final stations. The first stations denote stations without predecessors, whereas the final stations are stations without successors.

Table 2 shows the basic data of the two underbody lines. The total workload of the underbody line of the engine car $\left(T W_{1}\right)$ is 24 , and that of the electric car $\left(T W_{2}\right)$ is less than $T W_{1}$. This assumption is reasonable because the underbody structure of the electric car is simpler than that of the engine car. Hence, we set $T W_{2}$ to 21 , as shown in Table 1; however, it can be changed from 16.8 to 24 for developing a meta-model, as shown in Table 3. Subsequently, the total number of stations for the engine car $\left(N S_{1}\right)$ is 24 , and that for the electric car $\left(N S_{2}\right)$ is three. Hence, the process times of a station $\left(P T_{1}\right.$ and $\left.P T_{2}\right)$ can be calculated using Equation (1), of which the values are one and seven, respectively.

$$
P T_{i}=\frac{T W_{i}}{N S_{i}}
$$


Table 2. Basic data of two underbody lines.

\begin{tabular}{ccc}
\hline & Engine Car (Type 1) & Electric Car (Type 2) \\
\hline$T W_{i}$ & 24 & 21 \\
$N S_{i}$ & 24 & 3 \\
$P T_{i}$ & 1 & 7 \\
\hline
\end{tabular}

Table 3. Data for strategies 1, 2 and 3.

\begin{tabular}{cccccc}
\hline \multicolumn{2}{c}{ Electric Car (Type 2) } & \multicolumn{3}{c}{ Engine Car (Type 1) } \\
\hline \multirow{2}{*}{ Product-Mix } & Number of Cell Lines & \multicolumn{2}{c}{ Strategy $\mathbf{1}$} & \multicolumn{2}{c}{ Strategies 2 and 3 } \\
\cline { 3 - 6 } & & $N S_{\mathbf{1}}$ & $\boldsymbol{P T}_{\mathbf{1}}$ & $\boldsymbol{N S}_{\mathbf{1}}$ & $\boldsymbol{P T}_{\mathbf{1}}$ \\
\hline $0 \%$ & 0 & 24 & 1.0 & 24 & 1.0000 \\
$10 \%$ & 1 & 24 & 1.0 & 22 & 1.0909 \\
$20 \%$ & 2 & 24 & 1.0 & 20 & 1.2000 \\
$30 \%$ & 3 & 24 & 1.0 & 17 & 1.4118 \\
$40 \%$ & 4 & 24 & 1.0 & 15 & 1.6000 \\
$50 \%$ & 5 & 24 & 1.0 & 12 & 2.0000 \\
\hline
\end{tabular}

\subsection{Reconfiguration Strategies}

As the production volume of electric car increases, the production capacity of the underbody line of electric cars should be expanded by installing additional cell lines in parallel. Meanwhile, the production capacity of the underbody line of engine cars can be reduced by eliminating some stations and allocating more workloads to the remaining stations. The strategies are presented as follows.

\subsubsection{Strategy 1}

Although the production volume of engine cars decreases as the product mix increases (add new cell lines for electric cars), we did not change $N S_{1}$ and $P T_{1}$ (as shown in Table 3) and retained the current capacity of engine cars. In this case, additional space is required for installing the new underbody lines of electric cars.

\subsubsection{Strategy 2}

If the production volume of electric cars increases, we should eliminate some stations in the underbody lines of engine cars based on Table 3. In this case, the positions of stations to be eliminated are determined by the scenario shown in Figure 2. When the product mix becomes $10 \%$, we can eliminate the two workstations marked with (1) in Figure 2. Similarly, when the product mix increases to $20 \%$, we can eliminate the two workstations additionally which are marked with (2) in Figure 2. Subsequently, process time $P T_{1}$ can be recalculated using Equation (1). In strategy 2, we can reduce the additional spaces required for adding new cell lines for electric cars.

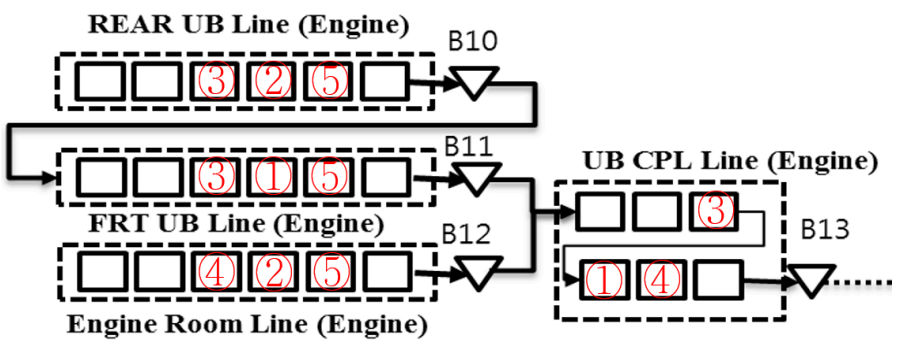

Figure 2. Positions of workstations to be eliminated in the underbody line for engine cars.

\subsubsection{Strategy 3}

In strategy 3 , the stations to be eliminated are substituted to buffers. Hence, the data and buffer positions for strategy 3 are the same as those in strategy 2. In strategy 3, additional spaces are required for expanding the underbody lines of electric cars. 
In the previous simulation study, the production rate of strategy 3 was better than those of strategies 1 and 2 [12].

\section{Procedure of Meta-Modeling}

The procedure to solve an optimization problem using a meta-model generally comprises two steps: the development of the meta-model and optimization using the developed meta-model. The specific procedure is shown in Figure 3.

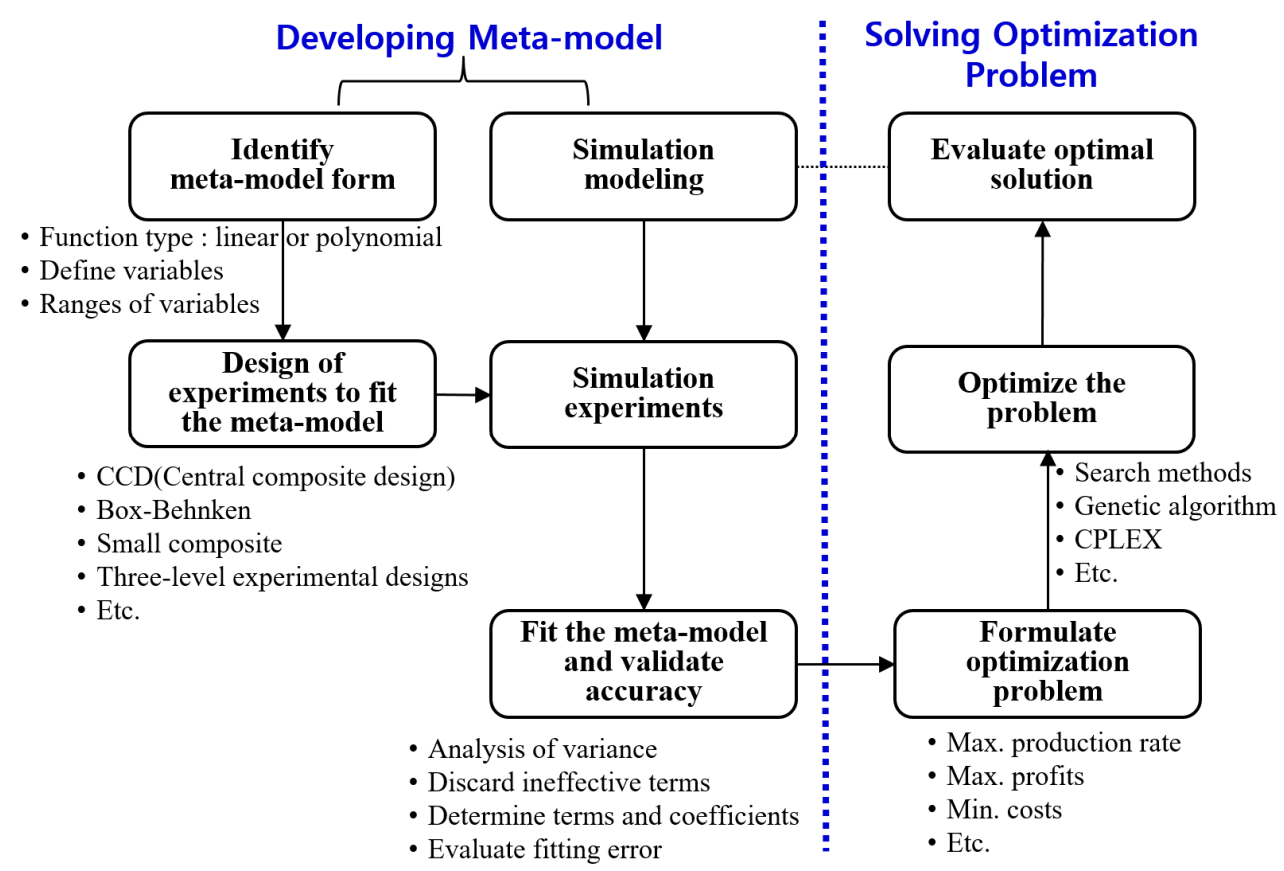

Figure 3. Overall processes of meta-modeling and optimization.

\subsection{Shape Determination of Meta-Model}

As described in Section 2.2, the most widely used meta-models in manufacturing system design problems are regression models [36-41]. In this study, the quadratic polynomial model was used. The form of the quadratic polynomial regression model used in this study can be expressed as shown in Equation (2). Hence, the model enables the analysis of the effects of the input variables on the objective function in the first-order, two-way interaction, and pure quadratic forms.

$$
f(\cdot)=\beta_{0}+\sum_{i=1}^{n} \beta_{i} x_{i}+\sum_{i=1}^{n} \beta_{i i} x_{i}^{2}+\sum_{i=1}^{n} \sum_{j=i+1}^{n} \beta_{i j} x_{i} x_{j}+\epsilon
$$

where $x_{i}$ denotes the value of the input variable; $\beta_{0}, \beta_{i}, \beta_{i i}$, and $\beta_{i j}$ are relative coefficients; $\epsilon$ is the error of the model.

\subsection{Grouping Input Variables}

The input variables affecting the production rate of the system were considered in the meta-model shown in Figure 1. They are as follows:

- 14 buffers between two sublines $\left(B_{1}-B_{14}\right)$

- Isolated efficiency of each station

- Mean time to failure

- Product mix of two car models

- Process time of electric car

The total number of variables was 18 , and the number of simulation experiments increased significantly for obtaining the accurate meta-model. Hence, the 14 buffers were 
grouped into eight, considering the similar structures of the sublines. For example, the front and rear structures of the sublines connected to $B_{1}, B_{2}, B_{3}$, and $B_{4}$ were similar; hence, the four buffers were grouped and represented as one variable.

Grouping variables may have two issues. One is the accuracy of the meta-model, and the other is the pattern of optimal buffer allocation. In our preliminary study, we developed a meta-model in a simplified body shop in which underbody sublines and attachment sublines were deleted from the system of Figure 1. The related coefficients of first-order terms and second-order terms were same in the meta-model. There were some differences in the coefficients of two-way interactions, but their effects were insignificant.

Grouping variables may slightly influence on the buffer allocation sequence during optimizing processes. However, in the near-optimal solution, the optimal buffer allocations for buffers in the same group were almost the same; hence, this grouping method is reasonable [19]. The results of the grouping are summarized in Table 4. Among the 12 variables included in the meta-model, $z_{1}-z_{8}$ were decision variables, whereas $z_{9}-z_{12}$ were control variables

Table 4. Definitions of input variables and the ranges of levels.

\begin{tabular}{|c|c|c|c|c|c|c|}
\hline \multicolumn{2}{|r|}{ Input Variables } & \multicolumn{5}{|c|}{ Range of Levels $(\alpha=2)$} \\
\hline Notation & Definition & $\operatorname{Min}\left(a_{i}\right)$ & Low & Medium & High & $\operatorname{Max}\left(b_{i}\right)$ \\
\hline$z_{1}$ & Buffer capacity of group $1\left(B_{1}, B_{2}, B_{3}, B_{4}\right)$ & 1 & 4 & 7 & 10 & 13 \\
\hline$z_{2}$ & Buffer capacity of group $2\left(B_{5}, B_{6}\right)$ & 1 & 4 & 7 & 10 & 13 \\
\hline$z_{3}$ & Buffer capacity of group $3\left(B_{7}, B_{9}\right)$ & 1 & 4 & 7 & 10 & 13 \\
\hline$z_{4}$ & Buffer capacity of group $4\left(B_{8}\right)$ & 1 & 4 & 7 & 10 & 13 \\
\hline$z_{5}$ & Buffer capacity of group $5\left(B_{10}, B_{12}\right)$ & 1 & 4 & 7 & 10 & 13 \\
\hline$z_{6}$ & Buffer capacity of group $6\left(B_{11}\right)$ & 1 & 4 & 7 & 10 & 13 \\
\hline$z_{7}$ & Buffer capacity of group $7\left(B_{13}\right)$ & 1 & 4 & 7 & 10 & 13 \\
\hline$z_{8}$ & Buffer capacity of group $8\left(B_{14}\right)$ & 1 & 2 & 3 & 4 & 5 \\
\hline$z_{9}$ & Efficiency of each station $(e)$ & 0.94 & 0.95 & 0.96 & 0.97 & 0.98 \\
\hline$z_{10}$ & Mean time to failure $(1 / f)$ & 160 & 200 & 240 & 280 & 320 \\
\hline$z_{11}$ & Product mix & 0.1 & 0.2 & 0.3 & 0.4 & 0.5 \\
\hline$z_{12}$ & The process time of each station for electric cars $\left(P T_{2}\right)$ & 5.6 & 6.2 & 6.8 & 7.4 & 8 \\
\hline
\end{tabular}

\subsection{Design of Experiments}

The meta-model of this study was designed based on the response surface methodology. Several experimental design methods exist, such as the three-level factorial design, central composite design (CCD), and Box-Behnken design [48]. In this study, simulation results were obtained according to the CCD experimental design method. The CCD is useful for building a second-order (quadratic) model with various input variables as it does not require a complete three-level factorial experiment.

The CCD can be designed by adding center point and axial point experiments to the two-level factorial design method. Hence, it has a relatively small number of experiments compared with other methods for estimating the quadratic polynomial model. If the number of input variables is 12 , then the total number of experiments of the three-level full factorial design method is $3^{12}=531,441$; however, the total number of experiments of the CCD is $2^{(12-p)}+2 \times 12+C_{p}$, where $p$ and $C_{p}$ are the size of fraction of the two-level full factorial design and the number of center points, respectively. We set $p=4$ and $C_{p}=8$; therefore, the total number of experiments was 288. In addition, the CCD has five levels of analysis, i.e., $(-\alpha,-1,0,1$, and $\alpha)$, for one variable. We set the value of $\alpha$, which is the distance from the center point to the axis point, to 2 .

The number of experiments for the fractional factorial 2-level designs of 12 factors is 128 with resolution level IV, but we set the number of experiments to 256 with resolution level VI for increasing the accuracy of the meta-model [49]. The design of experiments for 256 points was selected according to the plan recommended in RcmdrPlugin.DoE package in R package [50]. Eight experiments for center points were conducted by changing the random number streams. 
The level of each factor was determined within the ranges considered in practice. $z_{1}-z_{8}$ denote the buffer capacities of $B_{1}-B_{14} . z_{9}$ and $z_{10}$ are variables related to the isolated efficiency of each workstation defined in Equation (3), where $z_{9}$ is the efficiency $(e)$ in Equation (3), and $x_{10}$ denotes the mean time-to-failure (MTTF). When the values of $z_{9}$ and $z_{10}$ are determined, the mean time-to-repair (MTTR) can be calculated easily using Equation (3). In a mixed production environment, $z_{11}$ denotes the production volume ratio of an electric car when the total production amount of two cars is fixed as 1 ; hence, the production volume ratio of an engine car is $\left(1-z_{11}\right) . z_{12}$ denotes the process time of each station in the underbody cell of an electric car. The value of $z_{12}$ is 7 when the total workload is 21 , as in Table 1; however, we considered the $z_{12}$ range of 5.6-8.0 for developing the meta-model.

$$
e=\frac{M T T F}{M T T F+M T T R}
$$

Although the value of $z_{i}$ in Table 4 would be used directly for developing the metamodel, we defined a new variable, $x_{i}$, which normalizes the range of $x_{i}$ to $(-\alpha-\alpha)$, and $\alpha$ was set to 2 . This transformation was performed because the variables were inhomogeneous and the scales of $z_{i}$ differed; hence, the accuracy of the meta-model was not good enough. The relational expression for the normalization is shown in Equation (4), and we denote this transformation equation as $h_{i}\left(z_{i}\right)$.

$$
x_{i}=h_{i}\left(z_{i}\right)=-\alpha+\{\alpha-(-\alpha)\} \frac{z_{i}-a_{i}}{b_{i}-a_{i}}
$$

Table 5 shows part of the 288 experimental design points used for developing the meta-model and the corresponding simulation results. $P R_{s i m}$ denotes the production rate obtained by simulation, and the related $95 \%$ confidence intervals are $\pm 0.0008-0.0026$. Both the original level of $z_{i}$ and the normalized level of $x_{i}$ are also listed in Table 5. The simulation models were developed using ARENA ${ }^{\circledR}$; the simulation run time was set to 330,000 time units, including 30,000 warm up time units, and the number of replications was 10 . Hence, $P R_{\text {sim }}$ is calculated as the production quantities divided by 300,000 , where 300,000 is the annual production time $\left(250 \frac{\text { days }}{\text { year }} \times 20 \frac{\text { hours }}{\text { day }} \times 60 \frac{\text { minutes }}{\text { hour }}\right)$.

\begin{tabular}{|c|c|c|c|c|c|c|c|c|c|c|c|c|c|c|c|c|c|c|c|c|c|c|c|c|c|}
\hline \multirow{2}{*}{ Data Set } & \multicolumn{12}{|c|}{ Original Levels } & \multicolumn{12}{|c|}{ Normalized Levels } & \multirow[t]{2}{*}{$P R_{\text {sim }}$} \\
\hline & $z_{1}$ & $z_{2}$ & $z_{3}$ & $z_{4}$ & $z_{5}$ & $z_{6}$ & $z_{7}$ & $z_{8}$ & $z_{9}$ & $z_{10}$ & $z_{11}$ & $z_{12}$ & $x_{1}$ & $x_{2}$ & $x_{3}$ & $x_{4}$ & $x_{5}$ & $x_{6}$ & $x_{7}$ & $x_{8}$ & $x_{9}$ & $x_{10}$ & $x_{11}$ & $x_{12}$ & \\
\hline 1 & 4 & 4 & 4 & 4 & 4 & 4 & 4 & 2 & 0.95 & 200 & 0.2 & 6.2 & -1 & -1 & -1 & -1 & -1 & -1 & -1 & -1 & -1 & -1 & -1 & -1 & 0.2973 \\
\hline 2 & 10 & 4 & 4 & 4 & 4 & 4 & 4 & 2 & 0.97 & 280 & 0.4 & 7.4 & 1 & -1 & -1 & -1 & -1 & -1 & -1 & -1 & 1 & 1 & 1 & 1 & 0.5001 \\
\hline 255 & 4 & 10 & 10 & 10 & 10 & 10 & 10 & 4 & 0.95 & 200 & 0.2 & 6.2 & -1 & 1 & 1 & 1 & 1 & 1 & 1 & 1 & -1 & -1 & -1 & -1 & 0.3830 \\
\hline 256 & 10 & 10 & 10 & 10 & 10 & 10 & 10 & 4 & 0.97 & 280 & 0.4 & 7.4 & 1 & 1 & 1 & 1 & 1 & 1 & 1 & 1 & 1 & 1 & 1 & 1 & 0.5867 \\
\hline 257 & 1 & 7 & 7 & 7 & 7 & 7 & 7 & 3 & 0.96 & 240 & $\begin{array}{l}0.3 \\
0.3\end{array}$ & 6.8 & -2 & 0 & 0 & 0 & 0 & 0 & 0 & 0 & 0 & 0 & 0 & 0 & \\
\hline 258: & 13 & 7 & 7 & 7 & 7 & 7 & 7 & 3 & 0.96 & 240 & 0.3 & 3.8 & 2 & 0 & 0 & 0 & 0 & 0 & 0 & 0 & 0 & 0 & 0 & 0 & \\
\hline 279 & 7 & 7 & 7 & 7 & 7 & 7 & 7 & 3 & 0.96 & 240 & 0.3 & 5.6 & 0 & 0 & 0 & 0 & 0 & 0 & 0 & 0 & 0 & 0 & 0 & -2 & 0.4344 \\
\hline 280 & 7 & 7 & 7 & 7 & 7 & 7 & 7 & 3 & 0.96 & 240 & 0.3 & 8 & 0 & 0 & 0 & 0 & 0 & 0 & 0 & 0 & 0 & 0 & 0 & 2 & 0.4336 \\
\hline 281 & 7 & 7 & 7 & 7 & 7 & 7 & 7 & 3 & 0.96 & 240 & 0.3 & 6.8 & 0 & 0 & 0 & 0 & 0 & 0 & 0 & 0 & 0 & 0 & 0 & 0 & 0.4349 \\
\hline 288 & 7 & 7 & 7 & 7 & 7 & 7 & 7 & 3 & 0.96 & 240 & 0.3 & 6.8 & 0 & 0 & 0 & 0 & 0 & 0 & 0 & 0 & 0 & 0 & 0 & 0 & 0.4349 \\
\hline
\end{tabular}

Table 5. Experiment design for building the meta-model (reconfiguration strategy 3).

\subsection{Determination of the Meta-Model}

The data collected according to the experimental design in Table 5 were analyzed to estimate the coefficients $\beta_{0}, \beta_{i}, \beta_{i i}$, and $\beta_{i j}$ of the meta-model by variance analysis. Some ineffective terms were removed individually; the remaining terms and the analysis results are listed in Table 6. Considering traditional statistical principles, we should discard terms when the $\mathrm{p}$-values are greater than 0.05 . In this process, $x_{12}$ is a candidate for removal ( $p$-value-0.094), but we retained it. Pérez et al. [51] described that "There is no clear justification to the use of fixed significance, except by tradition". Hence, we pre-determined that all first-order terms $\left(x_{i}\right)$ would not be discarded, because they must be important and effective on the performance measure, and helpful for the expansion of the model. Similarly, 
the meta-models for reconfiguration strategies 1 and 2 were developed individually. Only the analysis data of strategy 3 are described herein.

Table 6. Result of regression analysis and selected terms (strategy 3).

\begin{tabular}{|c|c|c|c|c|c|c|c|c|c|}
\hline Term & Coef. & SE Coef. & $t$ & $p$ & Term & Coef. & SE Coef. & $t$ & $p$ \\
\hline Const. & 0.4340 & 0.0004 & 1070.01 & $<0.001$ & $x_{1} x_{7}$ & 0.0005 & 0.0001 & 4.07 & $<0.001$ \\
\hline$x_{1}$ & 0.0160 & 0.0001 & 143.57 & $<0.001$ & $x_{1} x_{9}$ & 0.0009 & 0.0001 & 8.01 & $<0.001$ \\
\hline$x_{2}$ & 0.0152 & 0.0001 & 136.60 & $<0.001$ & $x_{1} x_{10}$ & -0.0003 & 0.0001 & -2.51 & $<0.002$ \\
\hline$x_{3}$ & 0.0103 & 0.0001 & 92.03 & $<0.001$ & $x_{1} x_{11}$ & 0.0011 & 0.0001 & 9.38 & $<0.001$ \\
\hline$x_{4}$ & 0.0095 & 0.0001 & 85.42 & $<0.001$ & $x_{2} x_{3}$ & 0.0007 & 0.0001 & 5.90 & $<0.001$ \\
\hline$x_{5}$ & 0.0018 & 0.0001 & 15.90 & $<0.001$ & $x_{2} x_{5}$ & 0.0002 & 0.0001 & 2.07 & $<0.04$ \\
\hline$x_{6}$ & 0.0014 & 0.0001 & 12.99 & $<0.001$ & $x_{2} x_{6}$ & 0.0002 & 0.0001 & 2.06 & $<0.04$ \\
\hline$x_{7}$ & 0.0045 & 0.0001 & 40.57 & $<0.001$ & $x_{2} x_{9}$ & 0.0006 & 0.0001 & 5.17 & $<0.03$ \\
\hline$x_{8}$ & 0.0003 & 0.0001 & 2.89 & $<0.002$ & $x_{2} x_{10}$ & -0.0002 & 0.0001 & -2.00 & $<0.05$ \\
\hline$x_{9}$ & 0.1066 & 0.0001 & 956.30 & $<0.001$ & $x_{2} x_{11}$ & 0.0007 & 0.0001 & 6.14 & $<0.03$ \\
\hline$x_{10}$ & -0.0277 & 0.0001 & -248.76 & $<0.001$ & $x_{3} x_{4}$ & -0.0010 & 0.0001 & -9.21 & $<0.001$ \\
\hline$x_{11}$ & 0.0069 & 0.0001 & 62.28 & $<0.001$ & $x_{3} x_{7}$ & 0.0003 & 0.0001 & 2.99 & $<0.001$ \\
\hline$x_{12}$ & -0.0002 & 0.0001 & -1.68 & 0.094 & $x_{3} x_{9}$ & 0.0006 & 0.0001 & 5.68 & $<0.001$ \\
\hline$x_{1}^{2}$ & -0.0031 & 0.0003 & -10.18 & $<0.001$ & $x_{3} x_{10}$ & -0.0005 & 0.0001 & -4.31 & $<0.001$ \\
\hline$x_{2}^{2}$ & -0.0023 & 0.0003 & -7.52 & $<0.001$ & $x_{3} x_{11}$ & 0.0007 & 0.0001 & 6.17 & $<0.001$ \\
\hline$x_{3}^{2}$ & -0.0020 & 0.0003 & -6.70 & $<0.001$ & $x_{4} x_{9}$ & 0.0005 & 0.0001 & 4.40 & $<0.001$ \\
\hline$x_{4}^{2}$ & -0.0012 & 0.0003 & -3.84 & $<0.001$ & $x_{4} x_{10}$ & -0.0002 & 0.0001 & -2.01 & $<0.05$ \\
\hline$x_{7}^{2}$ & -0.0015 & 0.0003 & -4.80 & $<0.001$ & $x_{4} x_{11}$ & 0.0004 & 0.0001 & 3.46 & $<0.001$ \\
\hline$x_{9}^{2}$ & 0.0142 & 0.0003 & 46.69 & $<0.001$ & $x_{5} x_{6}$ & -0.0002 & 0.0001 & -2.14 & $<0.04$ \\
\hline$x_{10}^{2}$ & 0.0027 & 0.0003 & 8.97 & $<0.001$ & $x_{5} x_{7}$ & -0.0003 & 0.0001 & -2.36 & $<0.001$ \\
\hline$x_{11}^{2}$ & -0.0010 & 0.0003 & -3.29 & $<0.004$ & $x_{5} x_{11}$ & -0.0009 & 0.0001 & -8.16 & $<0.02$ \\
\hline$x_{1} x_{2}$ & -0.0020 & 0.0001 & -17.72 & $<0.001$ & $x_{6} x_{7}$ & -0.0004 & 0.0001 & -3.26 & $<0.001$ \\
\hline$x_{1} x_{3}$ & 0.0012 & 0.0001 & 10.81 & $<0.001$ & $x_{6} x_{11}$ & -0.0009 & 0.0001 & -7.96 & $<0.001$ \\
\hline$x_{1} x_{4}$ & 0.0005 & 0.0001 & 4.81 & $<0.001$ & $x_{7} x_{9}$ & 0.0003 & 0.0001 & 2.77 & $<0.001$ \\
\hline$x_{1} x_{5}$ & 0.0004 & 0.0001 & 3.42 & $<0.001$ & $x_{7} x_{11}$ & -0.0018 & 0.0001 & -15.51 & $<0.001$ \\
\hline$x_{1} x_{6}$ & 0.0003 & 0.0001 & 2.69 & $<0.01$ & $x_{10} x_{11}$ & 0.0007 & 0.0001 & 5.98 & $<0.001$ \\
\hline
\end{tabular}

The meta-models for estimating the production rates of strategies 1,2 , and 3 are denoted by $f_{1}(\boldsymbol{X}), f_{2}(\boldsymbol{X})$, and $f_{3}(\boldsymbol{X})$, respectively, and the detailed functions are shown in Equations (5), (6) and (7), respectively. Table 7 shows the result of variance analysis for the meta-model of strategy 3.

$$
\begin{aligned}
P R_{1}=f_{1}(X)= & 0.4316+0.0156 x_{1}+0.0151 x_{2}+0.0100 x_{3}+0.0095 x_{4}+0.0021 x_{5}+0.0018 x_{6}+0.0057 x_{7} \\
& +0.0003 x_{8}+0.1080 x_{9}-0.0283 x_{10}+0.0061 x_{11}-0.0002 x_{12}-0.0033 x_{1}^{2}-0.0025 x_{2}^{2} \\
& -0.0024 x_{3}^{2}-0.0013 x_{4}^{2}-0.0016 x_{7}^{2}+0.0145 x_{9}^{2}+0.0027 x_{10}^{2}-0.0009 x_{11}^{2}-0.0021 x_{1} x_{2} \\
& +0.0012 x_{1} x_{3}+0.0006 x_{1} x_{4}+0.0004 x_{1} x_{5}+0.0003 x_{1} x_{6}+0.0006 x_{1} x_{7}+0.0011 x_{1} x_{9} \\
& -0.0003 x_{1} x_{10}+0.0010 x_{1} x_{11}+0.0007 x_{2} x_{3}+0.0002 x_{2} x_{5}+0.0009 x_{2} x_{9}+0.0005 x_{2} x_{11} \\
& -0.0009 x_{3} x_{4}+0.0002 x_{3} x_{5}+0.0002 x_{3} x_{6}+0.0004 x_{3} x_{7}+0.0008 x_{3} x_{9}-0.0005 x_{3} x_{10} \\
& +0.0006 x_{3} x_{11}+0.0006 x_{4} x_{9}-0.0003 x_{4} x_{10}+0.0004 x_{4} x_{11}-0.0003 x_{5} x_{6}-0.0005 x_{5} x_{7} \\
& -0.0009 x_{5} x_{11}-0.0003 x_{6} x_{7}-0.0008 x_{6} x_{11}+0.0003 x_{7} x_{10}-0.0010 x_{7} x_{11}+0.0005 x_{10} x_{11} \\
P R_{2}=f_{2}(X)= & 0.4296+0.0153 x_{1}+0.0148 x_{2}+0.0099 x_{3}+0.0093 x_{4}+0.0025 x_{5}+0.0022 x_{6}+0.0060 x_{7} \\
& +0.0003 x_{8}+0.1063 x_{9}-0.0278 x_{10}+0.0066 x_{11}-0.0002 x_{12}-0.0032 x_{1}^{2}-0.0021 x_{2}^{2} \\
& -0.0021 x_{3}^{2}-0.0013 x_{4}^{2}-0.0007 x_{5}^{2}-0.0015 x_{7}^{2}+0.0143 x_{9}^{2}+0.0029 x_{10}^{2}-0.0021 x_{1} x_{2} \\
& +0.0012 x_{1} x_{3}+0.0006 x_{1} x_{4}+0.0005 x_{1} x_{5}+0.0007 x_{1} x_{7}+0.0008 x_{1} x_{9}+0.0009 x_{1} x_{11} \\
& +0.0006 x_{2} x_{3}+0.0002 x_{2} x_{6}+0.0006 x_{2} x_{9}+0.0007 x_{2} x_{11}-0.0009 x_{3} x_{4}+0.0005 x_{3} x_{7} \\
& +0.0006 x_{3} x_{9}-0.0004 x_{3} x_{10}+0.0007 x_{3} x_{11}+0.0005 x_{4} x_{9}+0.0004 x_{4} x_{11}-0.0005 x_{5} x_{7} \\
& -0.0009 x_{5} x_{11}-0.0007 x_{6} x_{11}+0.0005 x_{7} x_{9}-0.0011 x_{7} x_{11}+0.0002 x_{9} x_{11}+0.0004 x_{10} x_{11}
\end{aligned}
$$




$$
\begin{aligned}
P R_{3}=f_{3}(X)= & 0.4340+0.0160 x_{1}+0.0152 x_{2}+0.0103 x_{3}+0.0095 x_{4}+0.0018 x_{5}+0.0014 x_{6}+0.0045 x_{7} \\
& +0.0003 x_{8}+0.1066 x_{9}-0.0277 x_{10}+0.0069 x_{11}-0.0002 x_{12}-0.0031 x_{1}^{2}-0.0023 x_{2}^{2} \\
& -0.0020 x_{3}^{2}-0.0012 x_{4}^{2}-0.0015 x_{7}^{2}+0.0142 x_{9}^{2}+0.0027 x_{10}^{2}-0.0010 x_{11}^{2}-0.0020 x_{1} x_{2} \\
& +0.0012 x_{1} x_{3}+0.0005 x_{1} x_{4}+0.0004 x_{1} x_{5}+0.0003 x_{1} x_{6}+0.0005 x_{1} x_{7}+0.0009 x_{1} x_{9} \\
& -0.0003 x_{1} x_{10}+0.0011 x_{1} x_{11}+0.0007 x_{2} x_{3}+0.0002 x_{2} x_{5}+0.0002 x_{2} x_{6}+0.0006 x_{2} x_{9} \\
& -0.0002 x_{2} x_{10}+0.0007 x_{2} x_{11}-0.0010 x_{3} x_{4}+0.0006 x_{3} x_{7}+0.0006 x_{3} x_{9}-0.0005 x_{3} x_{10} \\
& +0.0007 x_{3} x_{11}+0.0005 x_{4} x_{9}-0.0002 x_{4} x_{10}+0.0004 x_{4} x_{11}-0.0002 x_{5} x_{6}-0.0003 x_{5} x_{7} \\
& -0.0009 x_{5} x_{11}-0.0004 x_{6} x_{7}-0.0009 x_{6} x_{11}+0.0003 x_{7} x_{9}-0.0018 x_{7} x_{11}+0.0007 x_{10} x_{11}
\end{aligned}
$$

Table 7. Result of analysis of variance (meta-model for strategy 3).

\begin{tabular}{clcccc}
\hline & Data Set & DF & Adj. SS & $\boldsymbol{F}$ & $p$ \\
\hline \multirow{4}{*}{ Model } & Linear & 12 & 3.4030 & 86,449 & $<0.001$ \\
& Quadratic & 8 & 0.0079 & 302.15 & $<0.001$ \\
& 2 way interaction & 31 & 0.0044 & 45.56 & $<0.001$ \\
& Total model & 51 & 3.4153 & 2671.62 & $<0.001$ \\
\hline \multirow{3}{*}{ Residual } & Lack of fit & 230 & 0.0008 & $1.1436 \times 10^{26}$ & $<0.001$ \\
& Pure error & 6 & 0 & & \\
& Total error & 236 & 0.0008 & & \\
\hline \multicolumn{5}{c}{ R-square (Adj.) $=99.98$} \\
\hline
\end{tabular}

\subsection{Validation of Meta-Model}

To validate the meta-model, we compared the production rates obtained from the simulation and the meta-model; the results are shown in Table 8. The data used for validation comprised two types: one contained 288 design experiment points, which were used for developing the meta-model; the other contained 45 points selected randomly from ranges (-1-1) and (-2-2) in Table 3. In Table 8, the absolute percentage error (APE), which is the index for measuring the difference between the simulation and meta-model results, is defined as shown in Equation (8). In the case of random points ranging from (-2-2), the maximum difference was relatively greater than those of others. Furthermore, the maximum difference occurred at the extreme value of the range of each variable ( -2 or 2$)$. This phenomenon is consistent with the fact that the meta-model is statistically meaningful only within the initial setting range (Low-High) of each variable. Hence, we conclude that the meta-model developed is efficient for optimizing problems.

$$
\mathrm{APE}=\frac{\left|P R_{\text {sim }}-P R_{\text {meta }}\right|}{P R_{\text {sim }}} \times 100
$$

Table 8. Validation of the meta-model (strategy 3).

\begin{tabular}{cccccc}
\hline \multirow{2}{*}{ Data Set } & \multirow{2}{*}{ Number of Points } & \multicolumn{3}{c}{ APE (\%) } \\
\cline { 4 - 6 } & & & Minimum & Mean & Maximum \\
\hline \multicolumn{2}{c}{ DOE points } & 288 & 0.00 & 0.29 & 2.91 \\
\hline \multirow{2}{*}{ Random points } & $\alpha=1$ & 45 & 0.00 & 0.21 & 0.57 \\
& $\alpha=2$ & 45 & 0.03 & 1.01 & 5.16 \\
\hline
\end{tabular}

\section{Application to Manufacturing System Design Problems}

\subsection{Production Rate Maximization Problem}

At first, the meta-models developed were applied to the BAP which maximizes production rate. The purposes of 5.1 are to estimate production rate and to see the pattern of optimal buffer allocation, when total buffer (TB), product mix, and reconfiguration strategies are predetermined. Then, this problem is generally defined as shown in Equations (9)-(12). Equation (9) defines the objective function, which is to maximize the production rate, where $i$ is the buffer group, $k$ is the total number of buffer positions ( $k=8$ herein), and $n$ is the total number of factors included in the meta-model, where the value of $z_{j}(j=k+1, \ldots, n)$ is predetermined as $v_{j}$. In this study, we developed a meta-model that is generally used for 
estimating the production rate; therefore, $z_{9}, z_{10}, z_{11}$ and $z_{12}$ were included in the metamodel. However, these control variables should be fixed for solving the BAP. Equation (10) shows the constraint related to the capacity of the total buffer (TB), where $c_{i}$ is the number of buffer positions in buffer group $i$, and $z_{i}$ is the capacity of buffer group $i$. Equation (11) defines the lower limit $\left(L B_{i}\right)$ and upper limit $\left(U B_{i}\right)$ of $z_{i}$. In addition, Equation (2) restricts $z_{i}$ to a non-negative integer. It is noteworthy that the meta-model developed uses the normalized variable $x_{i}$, not the original variable $z_{i}$. Hence, the objective function is redefined as shown in Equation (13), where $h_{i}\left(z_{i}\right)$ is the transformation function that transforms the value of $z_{i}$ to $x_{i}$, as defined in Equation (4).

$$
\begin{gathered}
\max P R(Z)=g\left(z_{1}, z_{2}, \ldots, z_{i}, \ldots, z_{k} \mid z_{k+1}=v_{k+1}, \ldots, z_{n}=v_{n}\right) \\
\text { s.t. } \sum_{i=1}^{k} c_{i} z_{i}=T B \\
L B_{i} \leq z_{i} \leq U B_{i} \leq T B, i=1,2 \ldots, k \\
z_{i}: \text { nonnegative integer, } i=1,2 \ldots, k \\
\max P R(X)=f\left(x_{1}, \ldots, x_{i}, \ldots, x_{k} \mid x_{k+1}=v^{\prime}{ }_{k+1}, \ldots, x_{n}=v_{n}^{\prime}\right) \\
=f\left(h_{1}\left(z_{1}\right), \ldots, h_{i}\left(z_{i}\right), \ldots, h_{k}\left(z_{k}\right) \mid x_{k+1}=h_{k+1}\left(v_{k+1}\right), \ldots, x_{n}=h_{n}\left(v_{n}\right)\right)
\end{gathered}
$$

The problem of reconfiguration strategy 3 was solved with CPLEX ${ }^{\circledR}$ because the efficiency of optimization algorithm was not our concern, and the results of the optimal buffer allocations are shown in Table 8 . In these experiments, $L B_{i}$ and $U B_{i}$ were set to 1 and 13 (except for $U B_{8}=5$ ), respectively, as defined in Table 4 . The values of $x_{9}, x_{10}, x_{11}$, and $x_{12}$ were set to medium values (level $=0$ ). The number in parenthesis below $z_{i}$ denotes the number of the buffer positions of group $i$, and the maximum value of the TB was 174 when all $z_{i}=U B_{i}$. The optimal buffer allocations obtained from CPLEX ${ }^{\circledR}$ were not always global optimal. Figure 4 shows the behavior of the production rate and relative optimal buffer allocation as TB increases. In this figure, reconfiguration strategy 3 always performs better than strategies 1 and 2. However, the gaps are negligible when the TB is greater than 150 .

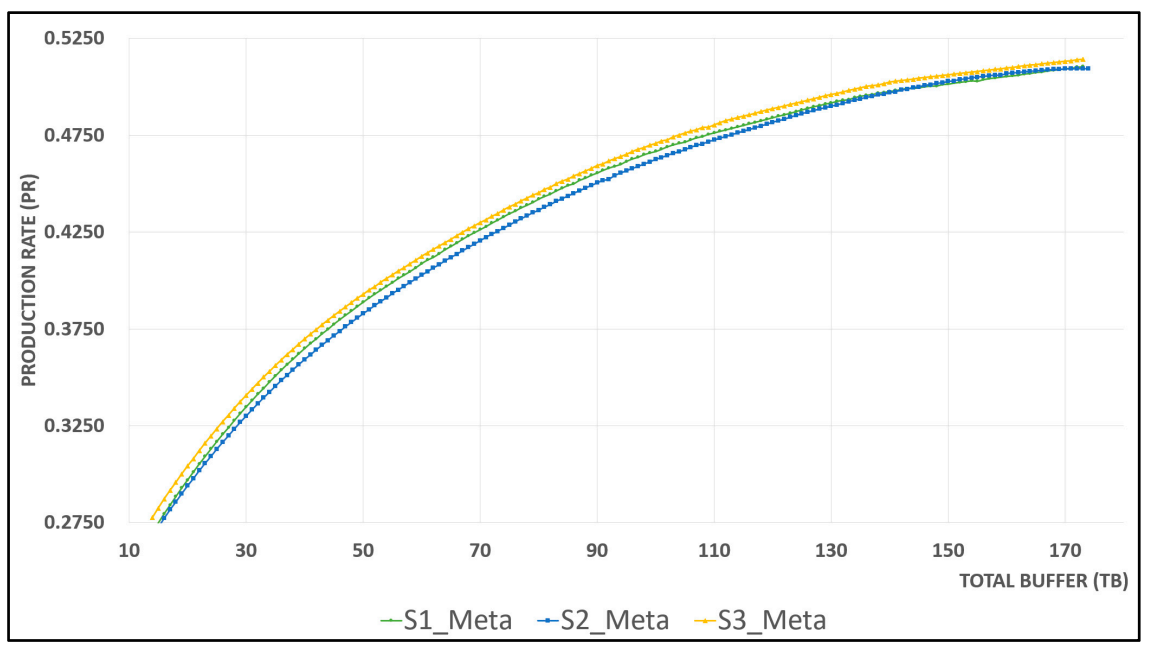

Figure 4. Behavior of production rate with total buffer (TB) and reconfiguration strategies.

The production rates obtained from the meta-model of strategy 3 were compared with those from simulation, as shown in Figure 5. The buffer allocations were optimized using the meta-model, and the same values were applied to simulation model. The detail optimization results are listed in Table 9. The meta-model overestimated the production rates when the TB was small; however, it changed to being underestimated when the TB increased. The gap between the two methods reduced in the middle of the ranges of the 
TB but enlarged at both ends of the ranges. This phenomenon depicts the limits of the meta-model. Table 10 shows the results of optimal buffer allocations and their production rates when product-mix is varied under the strategy 3 . The production rate increases as the increase of product-mix, because additional cell lines for electric car had a good influence on the total production volume. The patterns of optimal buffer allocations are a little bit different.

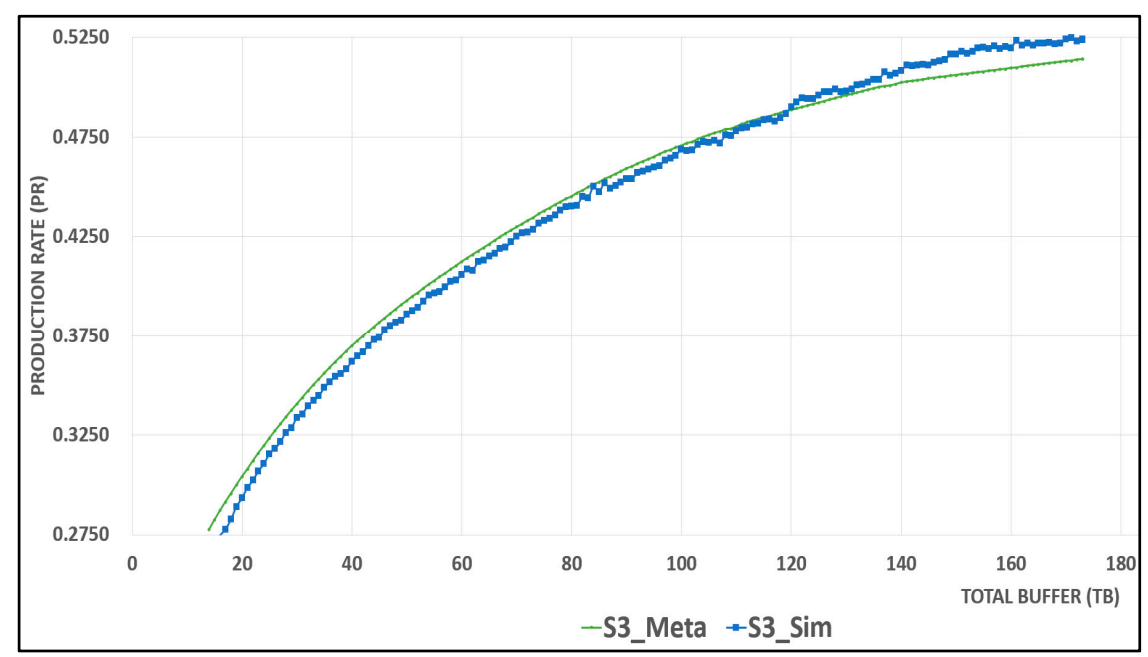

Figure 5. Comparison between meta-model and simulation (strategy 3).

Table 9. Solution of BAP using CPLEX ${ }^{\circledR}$ (strategy 3).

\begin{tabular}{|c|c|c|c|c|c|c|c|c|c|c|c|}
\hline \multirow[b]{2}{*}{ ТВ } & \multicolumn{8}{|c|}{ Optimal Buffer Allocation } & \multirow[b]{2}{*}{$P R_{m e t a}$} & \multirow[b]{2}{*}{$P R_{\text {sim }}$} & \multirow[b]{2}{*}{ APE (\%) } \\
\hline & $\begin{array}{l}z_{1} \\
\text { (4) }\end{array}$ & $\begin{array}{l}z_{2} \\
\text { (2) }\end{array}$ & $\begin{array}{l}z_{3} \\
\text { (2) }\end{array}$ & $\begin{array}{l}z_{4} \\
\text { (1) }\end{array}$ & $\begin{array}{l}z_{5} \\
\text { (2) }\end{array}$ & $\begin{array}{l}z_{6} \\
\text { (1) }\end{array}$ & $\begin{array}{l}z_{7} \\
\text { (1) }\end{array}$ & $\begin{array}{l}z_{8} \\
\text { (1) }\end{array}$ & & & \\
\hline 14 & 1 & 1 & 1 & 1 & 1 & 1 & 1 & 1 & 0.2775 & 0.2625 & -5.70 \\
\hline 15 & 1 & 1 & 1 & 2 & 1 & 1 & 1 & 1 & 0.2825 & 0.2693 & -4.90 \\
\hline 18 & 1 & 1 & 1 & 5 & 1 & 1 & 1 & 1 & 0.2957 & 0.2827 & -4.61 \\
\hline 19 & 1 & 2 & 1 & 4 & 1 & 1 & 1 & 1 & 0.3000 & 0.2892 & -3.72 \\
\hline 20 & 1 & 2 & 1 & 5 & 1 & 1 & 1 & 1 & 0.3041 & 0.2933 & -3.75 \\
\hline 21 & 1 & 3 & 1 & 4 & 1 & 1 & 1 & 1 & 0.3079 & 0.2987 & -3.11 \\
\hline 29 & 1 & 5 & 1 & 8 & 1 & 1 & 1 & 1 & 0.3374 & 0.3285 & -2.68 \\
\hline 30 & 1 & 5 & 1 & 8 & 1 & 1 & 2 & 1 & 0.3405 & 0.3336 & -2.07 \\
\hline 40 & 1 & 8 & 1 & 11 & 1 & 1 & 3 & 1 & 0.3697 & 0.3620 & -2.13 \\
\hline 50 & 1 & 10 & 2 & 13 & 1 & 1 & 5 & 1 & 0.3927 & 0.3861 & -1.71 \\
\hline 56 & 1 & 11 & 4 & 12 & 1 & 1 & 6 & 1 & 0.4048 & 0.3973 & -1.90 \\
\hline 57 & 1 & 11 & 4 & 12 & 1 & 1 & 7 & 1 & 0.4065 & 0.3995 & -1.74 \\
\hline 58 & 2 & 10 & 4 & 12 & 1 & 1 & 6 & 1 & 0.4085 & 0.4023 & -1.55 \\
\hline 59 & 2 & 11 & 3 & 13 & 1 & 1 & 6 & 1 & 0.4104 & 0.4030 & -1.82 \\
\hline 60 & 2 & 11 & 4 & 12 & 1 & 1 & 6 & 1 & 0.4124 & 0.4060 & -1.57 \\
\hline 70 & 3 & 12 & 5 & 13 & 1 & 1 & 7 & 1 & 0.4298 & 0.4251 & -1.10 \\
\hline 80 & 5 & 12 & 6 & 13 & 1 & 1 & 7 & 1 & 0.4451 & 0.4402 & -1.12 \\
\hline 90 & 6 & 12 & 8 & 13 & 1 & 1 & 9 & 1 & 0.4592 & 0.4539 & -1.18 \\
\hline 100 & 7 & 13 & 9 & 13 & 1 & 1 & 11 & 1 & 0.4706 & 0.4688 & -0.86 \\
\hline 110 & 8 & 13 & 12 & 13 & 1 & 1 & 11 & 1 & 0.4803 & 0.4780 & -0.48 \\
\hline 120 & 10 & 13 & 12 & 13 & 1 & 2 & 12 & 1 & 0.4886 & 0.4902 & 0.33 \\
\hline 130 & 10 & 13 & 12 & 13 & 1 & 13 & 11 & 1 & 0.4959 & 0.4980 & 0.42 \\
\hline 140 & 12 & 13 & 13 & 13 & 1 & 13 & 11 & 1 & 0.5023 & 0.5083 & 1.17 \\
\hline 150 & 13 & 13 & 13 & 13 & 3 & 13 & 12 & 2 & 0.5061 & 0.5165 & 2.01 \\
\hline 160 & 13 & 13 & 13 & 13 & 9 & 13 & 11 & 2 & 0.5096 & 0.5198 & 1.95 \\
\hline 170 & 13 & 13 & 13 & 13 & 12 & 13 & 11 & 5 & 0.5131 & 0.5240 & 2.08 \\
\hline 173 & 13 & 13 & 13 & 13 & 13 & 13 & 12 & 5 & 0.5140 & 0.5242 & 1.95 \\
\hline
\end{tabular}


Table 10. Results of buffer allocations for changing product-mix (strategy 3).

\begin{tabular}{|c|c|c|c|c|c|c|}
\hline \multirow{2}{*}{$\begin{array}{c}\text { Product-Mix } \\
\text { TB }\end{array}$} & \multicolumn{2}{|l|}{$20 \%$} & \multicolumn{2}{|l|}{$30 \%$} & \multicolumn{2}{|l|}{$40 \%$} \\
\hline & $\left(z_{1}, \ldots, z_{8}\right)^{*}$ & PR & $\left(z_{1}, \ldots, z_{8}\right)^{*}$ & PR & $\left(z_{1}, \ldots, z_{8}\right)^{*}$ & PR \\
\hline 50 & $(1,10,2,11,1,1,7,2)$ & 0.3825 & $(1,10,2,13,1,1,5,1)$ & 0.3927 & $(1,10,3,12,1,1,4,2)$ & 0.4023 \\
\hline 70 & $(3,11,5,13,1,1,9,1)$ & 0.4190 & $(3,12,5,13,1,1,7,1)$ & 0.4298 & $(3,12,6,13,1,1,5,1)$ & 0.4400 \\
\hline 90 & $(6,11,8,13,1,1,11,1)$ & 0.4475 & $(6,12,8,13,1,1,9,1)$ & 0.4592 & $(6,12,9,13,1,1,7,1)$ & 0.4700 \\
\hline 110 & $(9,12,10,13,1,1,13,1)$ & 0.4683 & $(8,13,12,13,1,1,11,1)$ & 0.4807 & $(9,13,11,13,1,1,9,1)$ & 0.4923 \\
\hline 130 & $(10,13,12,13,1,13,11,1)$ & 0.4859 & $(10,13,12,13,1,13,11,1)$ & 0.4959 & $(12,13,13,13,1,4,10,1)$ & 0.5062 \\
\hline 150 & $(12,13,13,13,5,13,13,1)$ & 0.4968 & $(13,13,13,13,3,13,12,2)$ & 0.5061 & $(13,13,13,13,2,13,10,5)$ & 0.5147 \\
\hline
\end{tabular}

* Optimal solution of buffer allocation.

\subsection{Profit Maximization Problem}

The second problem is a profit maximization problem (PMP) in which total profit is defined as the sum of the profit from the production rate, the cost savings from the reconfiguration of workstations, and reconstruction costs. In this problem both buffer allocation and reconfiguration strategy are determined at the same time.

$$
\begin{aligned}
& \operatorname{Max} T P\left(Z, y_{1}, y_{2}, y_{3}\right) \\
& =d_{1} \sum_{l=1}^{3}\left\{y_{l} \times g_{l}\left(z_{1}, z_{2}, \ldots, z_{i}, \ldots, z_{k} \mid z_{k+1}=v_{k+1}, \ldots, z_{n}=v_{n}\right)\right\} \\
& +\left(d_{2}+d_{3}-d_{4}\right) \times y_{2} \times \Delta+\left(d_{3}-d_{4}\right) \times y_{3} \times \Delta \\
& =d_{1} \sum_{l=1}^{3}\left\{y_{l} \times f_{l}\left(\left(h_{1}\left(z_{1}\right), \ldots, h_{i}\left(z_{i}\right), \ldots, h_{k}\left(z_{k}\right) \mid x_{k+1}=h_{k+1}\left(v_{k+1}\right), \ldots, x_{n}=h_{n}\left(v_{n}\right)\right\}\right.\right. \\
& +\left(d_{2}+d_{3}-d_{4}\right) \times y_{2} \times \Delta+\left(d_{3}-d_{4}\right) \times y_{3} \times \Delta \\
& \text { s.t. } \sum_{j=1}^{3}\left(y_{j} \times \sum_{i=1}^{k} c_{i} z_{i j}\right)=T B \\
& y_{1}+y_{2}+y_{3}=1 \\
& L B_{i} \leq z_{i j} \leq U B_{i} \leq T B, i=1,2 \ldots, k, \text { and } j=1, \ldots, 3 \\
& z_{i j}: \text { nonnegative integer, } i=1,2 \ldots, k \text { and } j=1, \ldots, 3 \\
& y_{1}, y_{2}, y_{3}: 0 \text { or } 1
\end{aligned}
$$

Note that is selected,

$g_{l}(\cdot)$ and $f_{l}(\cdot)$ : meta-models (Equations (9) and (13)) when reconfiguration strategy $l$

$d_{1}$ : revenue obtained from production rate,

$d_{2}$ : annual profit obtained from the elimination of floor space in a station,

$d_{3}$ : annual profit obtained from the uninstallation of robots in a station,

$d_{4}$ : reconstruction cost for eliminating a station,

$\Delta$ : the number of stations eliminated by the reconfiguration strategy, where

$$
\Delta= \begin{cases}2 & \text { if } z_{11}=0.1 \\ 4 & \text { if } z_{11}=0.2 \\ 7 & \text { if } z_{11}=0.3 \\ 9 & \text { if } z_{11}=0.4 \\ 12 & \text { if } z_{11}=0.5\end{cases}
$$

For the numerical example, we set $d_{1}$ as $\frac{\$ 1000 \times 300,000}{\text { car }}$ because the production quantity is calculated by $P R \times 300,000$. Although Liberopoulos [52] estimated the annual investment costs of a buffer space as $\$ 250-500$ plus $\$ 500-1000$ of depreciation, it is unreasonable for the floor space of a station. The land price of Korean automotive factory is very expensive about $\$ 1000 / \mathrm{ft}^{2}$, and the shop floor space required for a station in underbody line is at least $33 \mathrm{ft}^{2}$. Thus, we set $d_{2}=0.2 \times \frac{\$ 1000}{\mathrm{ft}^{2}} \times 33 \frac{\mathrm{ft}^{2}}{\text { station }}=\frac{\$ 6600}{\text { station }}$ where 0.2 is the opportunity cost of floor space. Since the number of robots installed in each station of underbody lines is $2-10$, 
we assumed that four robots can be uninstalled and reused when a station is eliminated. Thus, we set $d_{3}=0.1 \times 4 \frac{\text { robots }}{\text { station }} \times \frac{\$ 50,000}{\text { robot }}=\frac{\$ 20,000}{\text { station }}$, where 0.1 is the depreciation rate of robots. Finally, $d_{4}$ is set to $\$ 5000$ per station.

With these coefficient values, we solved this problem easily using a genetic algorithm supplied from MATLAB ${ }^{\circledR}$, because this problem is a nonlinear integer problem and difficult to solve using CPLEX ${ }^{\circledR}$. Figure 6 compares the total profits with respect to the reconfiguration strategies after optimal buffer allocations when the product-mix $\left(z_{11}\right)$ is set to $30 \%$. It means that strategy 3 is better than strategies 1 and 2 , and it means that $y_{3}=1$ when the PMP is solved. However, it is difficult to say that strategy 3 is better than strategies 1 or 2 with respect to statistical principles when TB has a large value, because the gaps among strategies are smaller than the confidence intervals. Nevertheless, strategy 3 must be selected if we have to choose only one, and there are any other preferences. Table 11 shows the examples of total profits, production rates obtained by meta-models, and the confidence intervals obtained from simulation experiments when same optimized values of variables are used for simulation models. The cross point between the strategies 1 and 2 $(\mathrm{TB}=142)$ becomes slightly smaller than that of the BAP problem in Section $5.1(\mathrm{~TB}=144)$. This phenomenon is due to the fact that the profit caused by the production rate is much bigger than the profit obtained from the reconfiguration.

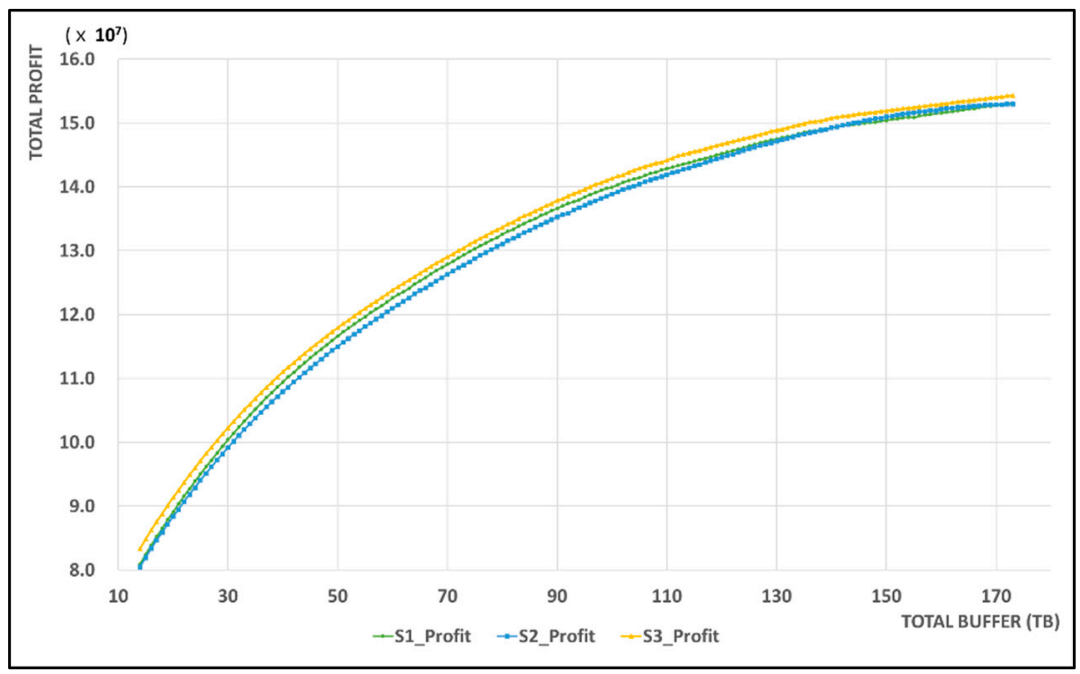

Figure 6. Comparison of total profits among reconfiguration strategies (product-mix $=30 \%$ ).

Table 11. Optimized results using meta-model and confidence intervals from simulation (product-mix $=30 \%$ ).

\begin{tabular}{|c|c|c|c|c|c|c|c|c|c|}
\hline \multirow{3}{*}{ TB } & \multicolumn{3}{|c|}{ Strategy 1} & \multicolumn{3}{|c|}{ Strategy 2} & \multicolumn{3}{|c|}{ Strategy 3} \\
\hline & \multicolumn{2}{|c|}{$\begin{array}{l}\text { Using Meta-Model } \\
\text { (Optimized) }\end{array}$} & \multirow{2}{*}{$\begin{array}{c}\text { Simulation } \\
95 \% \text { C.I. } \\
\text { of } \mathrm{PR}_{1}\end{array}$} & \multicolumn{2}{|c|}{$\begin{array}{l}\text { Using Meta-Model } \\
\text { (Optimized) }\end{array}$} & \multirow{2}{*}{$\begin{array}{c}\text { Simulation } \\
95 \% \text { C.I. of } \\
\mathrm{PR}_{2} \\
\end{array}$} & \multicolumn{2}{|c|}{$\begin{array}{l}\text { Using Meta-Model } \\
\text { (Optimized) }\end{array}$} & \multirow{2}{*}{$\begin{array}{c}\text { Simulation } \\
95 \% \text { C.I. } \\
\text { of } \mathrm{PR}_{3}\end{array}$} \\
\hline & $\underset{\left(\times 10^{8}\right)}{\mathbf{T P}}$ & $\mathbf{P R}_{1}$ & & $\underset{\left(\times 10^{8}\right)}{\text { TP }}$ & $\mathbf{P R}_{2}$ & & $\underset{\left(\times 10^{8}\right)}{\text { TP }}$ & $\mathrm{PR}_{3}$ & \\
\hline 70 & 1.2789 & 0.4263 & 0.0013 & 1.2634 & 0.4205 & 0.0017 & 1.2907 & 0.4298 & 0.0020 \\
\hline 90 & 1.3665 & 0.4555 & 0.0019 & 1.3529 & 0.4504 & 0.0009 & 1.3791 & 0.4592 & 0.0013 \\
\hline 110 & 1.4287 & 0.4762 & 0.0016 & 1.4195 & 0.4725 & 0.0014 & 1.4422 & 0.4803 & 0.0016 \\
\hline 130 & 1.4751 & 0.4917 & 0.0027 & 1.4719 & 0.4900 & 0.0015 & 1.4891 & 0.4959 & 0.0020 \\
\hline 150 & 1.5042 & 0.5014 & 0.0013 & 1.5101 & 0.5028 & 0.0014 & 1.5196 & 0.5061 & 0.0018 \\
\hline
\end{tabular}

Other observation is that total profit increases as the increase of TB within the range considered. If the TB increases much more, the total profit will decreases because production rate will not increase anymore, but the investment cost increases as the increase of buffer. 


\section{Conclusions}

Herein, the design problems of an automotive body shop have been considered, in which two types of cars (engine car and electric car) with different underbody structures were produced. Furthermore, three types of reconfiguration strategies were considered when the production volume of the electric car substituted that of the engine car gradually.

Most previous studies pertaining to the design problem of complex systems such as automotive body shops have used the simulation approach. However, the time for solving the optimization problem using simulations increased significantly when the system became more complex. Hence, we suggest quadratic polynomial meta-models based on simulations, and they have been applied to solve the two optimization problems. In meta-modeling, we grouped some buffer locations and presented them as one variable to reduce the number of variables, and the number of simulation experiments could be reduced. As a result, the number of simulation experiments for developing three metamodels was $288 \times 3=864$, and the simulation run time required on PC with an i-9(9900k) CPU was about $310 \mathrm{~s}$ for each experiment. On the contrary, the time required for solving the problems in Sections 5.1 and 5.2 were less than $0.1 \mathrm{~s}$ and $1.5 \mathrm{~s}$, respectively. If we solve these problems directly by simulation, the maximum number of simulation experiments for all enumerations could be estimated to $3 \times 13^{7} \times 5=9.4 \times 10^{8}$. Consequently, we have been able to reduce the number of experiments and the time required for optimization rather than attempting optimization by using simulations directly.

We included various control variables such as failure, product-mix and process times for expanding the meta-models to various aspects of the automotive body shop. Hence, the estimation of production rates and optimization can be carried easily when the system configurations are changed.

Practically, we suggested the concept of parallel cell lines for the underbody sub-lines of electric car, and compared three reconfiguration strategies when electric car substitutes engine car in the near future. Therefore, it was possible to optimize the buffer allocation and the reconfiguration strategy simultaneously, and it would be helpful to automotive manufacturers.

It was found that strategy 3 was superior to the other two reconfiguration strategies, when considering the current cost structure in the two optimization problems considered. However, strategy 2 will be meaningful if the cost savings due to reconfiguration are relatively bigger, or if the constraint of available space for installing new parallel cell lines is limited when the product-mix of electric car increases.

As a further research topic, we can consider a new problem of finding the optimal stepwise reconfiguration strategies by years that could maximize the profit for the entire planning periods, when the product-mix of electric car continues to increase. The inventory cost of WIP (work-in-process) can be included in the maximizing profit model, because the increase of TB will results in the level of WIPs and manufacturing lead times.

Author Contributions: D.H.M. conceived the research; D.H.M. and Y.W.S. designed the research; D.H.M. developed the framework, optimization models and prepared the manuscript; D.O.K. developed simulation models, meta-models and conducted experiments; D.H.M., D.O.K. and Y.W.S. validated all processes and data. All authors have read and agreed to the published version of the manuscript.

Funding: This work was supported by the Basic Research Program of the [National Research Foundation of Korea (NRF)] under Grant [NRF-2019R1F1A1057692] and [NRF-2018R1D1A1A09083352].

Institutional Review Board Statement: Not applicable.

Informed Consent Statement: Not applicable.

Data Availability Statement: Not applicable.

Conflicts of Interest: The authors declare no conflict of interest. 


\section{References}

1. Omar, M.A. The Automotive Body Manufacturing Systems and Processes; John Wiley \& Sons: New York, NY, USA, 2011.

2. Naitoh, T.; Yamamoto, K.; Kodama, Y.; Honda, S. The Development of an Intelligent Body Assembly System. In Transforming Automobile Assembly; Shimokawa, S., Jürgens, U., Fujimoto, T., Eds.; Springer: Berlin/Heidelberg, Germany, 1997; pp. 121-132.

3. Rooks, B. Rover 75 sets new standards in body-in-white assembly. Ind. Rob. 1999, 26, 342-348. [CrossRef]

4. Moon, D.H.; Cho, H.I.; Kim, H.S.; Sunwoo, H.; Jung, J.Y. A case study of the body shop design in an automotive factory using 3D simulation. Int. J. Prod. Res. 2006, 44, 4121-4135. [CrossRef]

5. Hansen, J.O.; Kampker, A.; Triebs, J. Approaches for flexibility in the future automobile body shop: Results of a comprehensive cross-industry study. Procedia CIRP 2018, 72, 995-1002. [CrossRef]

6. Giampieri, A.; Ling-Chin, J.; Ma, Z.; Smallbone, A.; Roskilly, A.P. A review of the current automotive manufacturing practice from an energy perspective. Appl. Energy 2020, 261, 114074. [CrossRef]

7. Frieske, B.; Kloetzke, M.; Mauser, F. Trends in vehicle concept and key technology development for hybrid and battery electric vehicles. In 2013 World Electric Vehicle Symposium and Exhibition (EVS27); IEEE: Barcelona, Spain, 2013; pp. 1-12. [CrossRef]

8. Casper, R.; Sundin, E. Electrification in the automotive industry: Effects in remanufacturing. J. Remanuf. 2020. [CrossRef]

9. Koren, Y.; Heisel, U.; Jovane, F.; Moriwaki, T.; Pritschow, G.; Ulsoy, G.; Van Brussel, H. Reconfigurable manufacturing systems. CIRP Ann. Manuf. Technol. 1999, 48, 527-540. [CrossRef]

10. Koren, Y.; General, R.M.S. characteristics. Comparison with dedicated and flexible systems. In Reconfigurable Manufacturing Systems and Transformable Factories; Dashchenko, A.I., Ed.; Springer: Berlin/Heidelberg, Germany, 2006; pp. 27-45. [CrossRef]

11. Bortolini, M.; Galizia, F.G.; Mora, C. Reconfigurable manufacturing systems: Literature review and research trend. J. Manuf. Syst. 2018, 49, 93-106. [CrossRef]

12. Moon, D.H.; Kim, D.O.; Lee, Y.H.; Shin, Y.W. A simulation study on the effect of reconfiguration strategy in an automotive body shop considering the change of product-mix. In Proceedings of the 9th International Conference on Operations Research and Enterprise Systems (ICORES 2020), Valletta, Malta, 22-24 February 2020; pp. 430-435. [CrossRef]

13. Muhl, E.; Charpentier, P.; Chaxel, F. Optimization of physical flows in an automotive manufacturing plant: Some experiments and issues. Eng. Appl. Artif. Intell. 2003, 16, 293-305. [CrossRef]

14. Tahar, R.B.M.; Adham, A.A.J. Design and analysis of automobiles manufacturing system based on simulation model. Mod. Appl. Sci. 2010, 4, 130-134. [CrossRef]

15. Spieckermann, S.; Gutenschwager, K.; Heinzel, H.; Voß, S. Simulation-based optimization in the automotive industry-A case study on body shop design. Simulation 2000, 75, 276-286.

16. Feno, M.R.; Cauvin, A.; Ferrarini, A. Conceptual design and simulation of an automotive body shop assembly line. IFAC Proc. Vol. 2014, 47, 760-765. [CrossRef]

17. Kim, H.S.; Wang, G.; Shin, Y.W.; Moon, D.H. Comparison of the two layout structures in automotive body shops considering failure distributions. J. Korean Inst. Ind. Eng. 2015, 41, 470-480. [CrossRef]

18. Moon, D.H.; Nam, Y.S.; Kim, H.S.; Shin, Y.W. Effect of part transfer policies in two types of layouts in automotive body shops. Int. J. Ind. Eng. Theory 2017, 24, 194-206.

19. Moon, D.H.; Nam, Y.S.; Shin, Y.W. Effects of additional sub-lines and buffer allocation on the system performance in an automotive body shop. J. Korean Soc. Supply Chain Manag. 2016, 16, 135-145.

20. Moon, D.H.; Lee, Y.H.; Shin, Y.W. The effect of mixed-model production in automotive body shops considering assembly methods and part transfer policies. J. Korean Inst. Ind. Eng. 2018, 44, 391-403. [CrossRef]

21. Kahan, T.; Bukchin, Y.; Menassa, R.; Ben-Gal, I. Backup strategy for robots' failures in an automotive assembly system. Int. J. Prod. Econ. 2009, 120, 315-326. [CrossRef]

22. Azzi, A.; Battini, D.; Faccio, M.; Persona, A. Mixed model assembly system with multiple secondary feeder lines: Layout design and balancing procedure for ATO environment. Int. J. Prod. Res. 2012, 50, 5132-5151. [CrossRef]

23. Azzi, A.; Battini, D.; Faccio, M.; Persona, A. Sequencing procedure for balancing the workloads variations in case of mixed model assembly system with multiple secondary feeder lines. Int. J. Prod. Res. 2012, 50, 6081-6098. [CrossRef]

24. Faccio, M.; Bottin, M.; Rosati, G. Collaborative and traditional robotic assembly: A comparison model. Int. J. Adv. Manuf. Technol. 2019, 102, 1355-1372. [CrossRef]

25. Gershwin, S.B. Manufacturing System Engineering; Prentice-Hall International: London, UK, 1994.

26. Li, J.S.; Meerkov, S.M. Production Systems Engineering; Springer: New York, NY, USA, 2009.

27. Dallery, Y.; Gershwin, S.B. Manufacturing flow line systems: A review of models and analytical results. Queueing Syst. 1992, 12, 3-94. [CrossRef]

28. Papadopoulos, H.T.; Heavey, C. Queueing theory in manufacturing systems analysis and design: A classification of models for production and transfer lines. Eur. J. Oper. Res. 1996, 92, 1-27. [CrossRef]

29. Altiok, T. Performance Analysis of Manufacturing Systems; Springer: New York, NY, USA, 1997.

30. Li, J.S.; Blumenfeld, D.E.; Huang, N.; Alden, J.M. Throughput analysis of production systems: Recent advances and future topics. Int. J. Prod. Res. 2009, 47, 3823-3851. [CrossRef]

31. Papadopoulos, C.T.; Li, J.; O’Kelly, M.E.J. A classification and review of timed Markov models of manufacturing systems. Comput. Ind. Eng. 2019, 128, 219-244. [CrossRef] 
32. Tancrez, J.S. A decomposition method for assembly/disassembly systems with blocking and general distributions. Flex. Serv. Manuf. J. 2020, 32, 272-296. [CrossRef]

33. Cohen, Y.; Faccio, M.; Pilati, F.; Tao, X. Design and management of digital manufacturing and assembly systems in the Industry 4.0 era. J. Adv. Manuf. Technol. 2019, 105, 3565-3577. [CrossRef]

34. Kleijnen, J.P.C. Kriging metamodeling in simulation: A review. Eur. J. Oper. Res. 2009, 192, 707-716. [CrossRef]

35. Can, B.; Heavey, C. Comparison of experimental designs for simulation-based symbolic regression of manufacturing systems. Comput. Ind. Eng. 2011, 61, 447-462. [CrossRef]

36. Kleijnen, J.P.C.; Standridge, C.R. Experimental design and regression analysis in simulation: An FMS case study. Eur. J. Oper. Res. 1988, 33, 257-261. [CrossRef]

37. Durieux, S.; Pierreval, H. Regression metamodeling for the design of automated manufacturing system composed of parallel machines sharing a material handling resource. Int. J. Prod. Econ. 2004, 89, 21-30. [CrossRef]

38. Motlagh, M.M.; Azimi, P.; Amiri, M.; Madraki, G. An efficient simulation Optimization methodology to solve a multi-objective problem in unreliable unbalanced production lines. Expert Syst. Appl. 2019, 138, 112836. [CrossRef]

39. Dengiz, B.; Akbay, K.S. Computer simulation of a PCB production line: Meta-modeling approach. Int. J. Prod. Econ. 2000, 63, 195-205. [CrossRef]

40. Um, I.S.; Cheon, H.J.; Lee, H.C. The simulation design and analysis of a flexible manufacturing system with automated guided vehicle system. J. Manuf. Sys. 2009, 28, 115-122. [CrossRef]

41. Dengiz, B.; Tansel, İ.; Belgin, O. A meta-model based simulation optimization using hybrid simulation-analytical modeling to increase the productivity in automotive industry. Math. Comput. Simulat. 2016, 120, 120-128. [CrossRef]

42. Weiss, S.; Schwarz, J.A.; Stolletz, R. The buffer allocation problem in production lines: Formulations, solution methods, and instances. IISE Trans. 2019, 51, 456-485. [CrossRef]

43. Chan, F.T.S.; Ng, E.Y.H. Comparative evaluations of buffer allocation strategies in a serial production line. Int. J. Adv. Manuf. Technol. 2002, 19, 789-800. [CrossRef]

44. Amiri, M.; Mohtashami, A. Buffer allocation in unreliable production lines based on design of experiments, simulation, and genetic algorithm. Int. J. Adv. Manuf. Technol. 2012, 62, 371-383. [CrossRef]

45. Papadopoulos, C.T.; O'Kelly, M.E.J.; Tsadiras, A.K. A DSS for the buffer allocation of production lines based on a comparative evaluation of a set of search algorithms. Int. J. Prod. Res. 2013, 51, 4175-4199. [CrossRef]

46. Demir, L.; Tunali, S.; Eliiyi, D.T. The state of the art on buffer allocation problem: A comprehensive survey. J. Intell. Manuf. 2014, 25, 371-392. [CrossRef]

47. Liberopoulos, G. Comparison of optimal buffer allocation in flow lines under installation buffer, echelon buffer, and CONWIP policies. Flex. Serv. Manuf. J. 2020, 32, 297-365. [CrossRef]

48. Bezerra, M.A.; Santelli, R.E.; Oliveira, E.P.; Villar, L.S.; Escaleira, L.A. Response surface methodology (RSM) as a tool for optimization in analytical chemistry. Talanta 2008, 76, 965-977. [CrossRef]

49. Grömping, U. R package DoE.base for factorial experiments. J. Stat. Softw. 2018, 85, 1-41. [CrossRef]

50. Groemping, U.; John, F. Package 'RcmdrPlugin.DoE' (R Package Version 0.12-3). 2014. Available online: https:/ / cran.r-project. org/web/packages/RcmdrPlugin.DoE/index.html (accessed on 20 August 2020).

51. Pérez, M.E.; Pericchi, L.R. Changing statistical significance with the amount of information: The adaptive $\alpha$ significance level. Stat. Probab. Lett. 2014, 85, 20-24. [CrossRef] [PubMed]

52. Liberopoulos, G. Performance evaluation of a production line operated under an echelon buffer policy. IISE Trans. 2018, 50, 161-177. [CrossRef] 